\title{
Editorial
}

\section{Quarter century of Medical Journal of Indonesia: Between national and international publications for building capacity building}

\author{
Nafrialdi, Felix F. Widjaja
}

Medical Journal of Indonesia

The appearance of volume 26, number 4, 2017 of the Medical Journal of Indonesia (MJI) represents the closing of the publication year 2017. For the MJI, this year marks a quarter century of its age. It is indeed a quite long period for a scientific journal to become a highly reputable and widely known media for publication. Indeed, a significant leap has been done by the MJI along with its acceptation in the Scopus three years ago. It signifies that MJI's readability is widening worldwide. This success would not be accomplished without the quality and the regularity of MJI publication led by the previous editor-in-chief since MJI was born, Abdul Bari Saifuddin, Isnani A.S. Suryono, Nafrialdi, and now being led by Agus Rizal Hamid.

Being indexed in an international indexing company is an attracting factor for local researchers, and hopefully also for regional and international researchers to submit their manuscript to MJI. Hence, it is revealed that manuscript submission increased significantly. MJI is now flooded with manuscript submission, which should be seen as a good news. We hope that more quantity will bring better quality. Sufficient amount of manuscript enables us to increase the quality of the journal by selecting higher-quality papers to be published.

On the other hand, increased submission means a much bigger burden for editorial team and reviewers, unless more personnel are recruited. If not, this could eventually end with manuscript stagnation. On the other hand, it has been known that nowadays medical professionals "flooded" by articles. It is also our responsibility as a journal to assure the quality of published articles as an "ethical" knowledge.

Regulation of the Ministry of Research Technology and Higher Education number 44, 2015 stated that publication of research work is necessary for post-graduate student before a candidate is allowed to pass his/her final examination. For master degree program, the publication can be done in accredited journals with national or international reputation, while for a Ph.D. program, publication should be in a highly reputable international journal. This regulation gives a strong booster for the researchers to make publications and will bring important benefits to the national scope. International publication is one of the important points of measurement for university ranking. However, on the point of view of the local journal, this call brings some negative impact. If all the top quality researches done by Ph.D students are published in the high reputable international journal, then only second or third quality manuscripts left for local journals. Even though this local journals have been internationally indexed, their quality and citation are still very low, even some if it has no citation. We also can not solely assess a journal citation with Impact Factor from Thomson Reuters or CiteScore from Elsevier. Many articles in local journals are cited by other local journals that are still not indexed by Web of Science or Scopus which make them not calculated in Impact Factor or CiteScore. Ministry of Research Technology and Higher Education has introduced Sinta (Science and Technology Index) to observe the citation of accredited local journal by combining data from Scopus and Google Scholar. We hope that what meant by international publication not only limited to overseas journal, but will also cover internationally-indexed local journal with good citation locally and internationally.

It is interesting to note an article written by Prof. Idrus Affandi in a local journal/newspaper called "Kabar Pendidikan" edition January 6- 2018 urging to stop submitting to international publication. This author argued that obligation to publish in an international journal can be interpreted as a sort 
of intellectual colonialism. Research findings from our country, he proposed, should be particularly readable for our community. This opinion seems right in certain aspects, but a complete cessation of international publication will lead to much more serious consequences that will end with the downgrading of national scientific quality. Participation at the international scientific community, including publication, is inevitable for research capacity building. Without international competition, our country will be left behind.

In conclusion, publishing in a journal with international reputation is a must to raise our position among the scientific community in the world, while national publication is also important to support the local journal increasing their quality.

pISSN: 0853-1773 • eISSN: 2252-8083 • https://doi.org/10.13181/mji.v26i4.2604 • Med J Indones. 2017;26:237-8

Corresponding author: Nafrialdi, nafrialdi@yahoo.com

Copyright @ 2017 Authors. This is an open access article distributed under the terms of the Creative Commons Attribution-NonCommercial 4.0 International License (http://creativecommons.org/licenses/by-nc/4.0/), which permits unrestricted non-commercial use, distribution, and reproduction in any medium, provided the original author and source are properly cited. 